\title{
Struktur Lamun di Zona Intertidal Kecamatan Tabukan Selatan, Kabupaten Kepulauan Sangihe, Sulawesi Utara \\ (Structure of Seagrass on Intertidal Zone of Southern Tabukan Sub-District, Sangihe Islands District, North Sulawesi)
}

\author{
Stevi Tumadang ${ }^{1)}$, Ratna Siahaan ${ }^{1 *}$, Pience V. Maabuat ${ }^{1 *}$ \\ 1) Jurusan Biologi, Fakultas Matematika dan IImu Pengetahuan Alam, \\ Universitas Sam Ratulangi - Manado 95115 \\ *Email korespondensi:ratnasiahaan@unsrat.ac.id
}

Diterima 1 Juli 2019, diterima untuk dipublikasi 5 Agustus 2019

\begin{abstract}
Abstrak
Lamun memiliki fungsi ekologis dan nilai ekonomi yang penting. Penelitian berujuan untuk menganalisis struktur lamun di tiga area intertidal yaitu Pantai Karurung (Desa Salurang), Pantai Palareng (Desa Palareng), dan Pantai Galogong (Desa Batuwingkung), Kecamatan Tabukan Selatan, Kabupaten Kepulauan Sangihe, Sulawesi Utara. Metode purposive sampling digunakan dalam penentuan tempat sampling dengan pengambilan sampel yang menggunakan metode line transect. Jenis-jenis lamun yang ditemukan sebanyak tujuh (7) jenis yaitu Cymodocea rotundata, Cymodocea serrulata, Enhalus acoroides, Halodule uninervis, Halophila ovalis, Syringodium isoetifolium, dan Thalassodendron ciliatum. Lamun S. isoetifolium memiliki nilai Kepadatan Relatif tertinggi di ketiga stasiun berturut-turut, yaitu 48,60\%, 43,31\%, dan 44,08\%. Secara berturut-turut, lamun S. isoetifolium juga memiliki Indeks Nilai Penting tertinggi di ketiga stasiun, yaitu 74,92\%, 65,31\%, dan 70,75\%. Keanekaragaman jenis lamun pada ketiga stasiun tergolong sedang dengan Indeks Keanakeragaman Shannon-Wiener $\left(H^{\prime}\right)$ secara berturut-turut, yaitu 1,52; 1,61; dan 1,23. Secara keseluruhan, keanekaragaman jenis lamun di Kecamatan Tabukan Selatan tergolong sedang $\left(H^{\prime}: 1,59\right)$.

Katakunci : struktur lamun, Tabukan Selatan, Pantai Karurung, Pantai Palareng, Pantai Galoghong, Kepulauan Sangihe
\end{abstract}

\begin{abstract}
Seagrasses have important ecological functions and economic values. The study was carried out to analyze structure and distribution of seagrass on three intertidal areas, i.e. Karurung Beach (Salurang Village), Palareng Beach (Palareng Village), and Galogong Beach (Batuwingkung Village), South Tabukan District, Sangihe Islands Regency, North Sulawesi. The purposive sampling method was applied in choosing sampling locations. The line transect method was used for sampling seagrass. Seagrass species found were seven (7) species, i.e. Cymodocea rotundata, Cymodocea serrulata, Enhalus acoroides, Halodule uninervis, Halophila ovalis, Syringodium isoetifolium, and Thalassodendron ciliatum. Seagrass $S$. isoetifolium had the highest Relative Density Value in three locations, i.e. $48.60 \%, 43.31 \%$, and $44.08 \%$ perspectively. The seagrass $S$. isoetifolium also had the highest Important Value Index i.e. $74.92 \%, 65.31 \%$, and $70.75 \%$ perspectively. The diversity of seagrass species in three stations was classified into moderate with Shannon-Wiener Biodiversity Index $\left(H\right.$ ') i.e. 1.52; 1.61; and 1.23 perspectively. The overall $H^{\prime}$ of seagrass of South Tabukan was classified into moderate ( $H$ ': 1.59).

Key words: $\quad$ seagrass structure, South Tabukan, Karurung Beach, Palareng Beach, Galoghong Beach, Sangihe Islands
\end{abstract}




\section{PENDAHULUAN}

Indonesia merupakan negara kepulauan yang kaya akan sumber daya hayati laut. Kekayaan sumberdaya hayati laut ini tersebar di Indonesia, salah satunya di Kepulauan Sangihe. Salah satu sumberdaya hayati laut yang ditemukan di intertidal Kepulauan Sangihe, yaitu lamun.

Lamun sering ditemukan di mmbentuk suatu padang yang terdiri dari satu jenis ataupun lebih atau yang disebut padang lamun. Secara ekologis, lamun memiliki banyak fungsi, diantaranya sebagai tempat pemijahan, habitat, produsen, dan penyangga (Rahmawati et al. 2014). Secara ekonomis, lamun dapat bermanfaat sebagai bahan makanan bagi manusia (Wagey 2013).

Penelitian bertujuan untuk menganalisis struktur lamun di interidal Kecamatan Tabukan Selatan, Kabupaten Kepualauan Sangihe. Penelitian diharapkan dapat menjadi data base tentang lamun di Kepulaauan Sangihe yang akan bermanfaat dan meningkatkan partisipasi masyarakat dalam upaya melindungi lamun.

\section{METODE}

Penelitian dilaksanakan di area intertidal di tiga pantai yaitu Pantai Karurung - Desa Salurang (Stasiun I), Pantai Palareng - Desa Palareng (Stasiun II), dan Pantai Galoghong Desa Batuwingkung (Stasiun III). Lokasi penelitian tersebut termasuk Kecamatan Tabukan Selatan, Kabupaten Kepulauan Sangihe, Provinsi Sulawesi Utara.

Pencuplikan sebanyak tiga (3) kali dilakukan di tiap stasiun. Stasiun I berada di titik-titik koordinat $03^{\circ} 28^{\prime} 04,55^{\prime \prime}$ LU dan $125^{\circ} 39^{\prime} 54,46^{\prime \prime}$ BT; $03^{\circ} 28^{\prime} 05,26^{\prime \prime}$ LU dan $125^{\circ}$ 39'56,43" BT; 03⒉ $8^{\prime} 00,84^{\prime \prime}$ LU dan $125^{\circ} 39^{\prime} 54,89^{\prime \prime}$ BT; 0328'01,47" LU dan $125^{\circ} 39^{\prime} 57,15^{\prime \prime}$ BT. Stasiun II di titik-titik koordinat $03^{\circ} 30^{\prime} 39,81^{\prime \prime}$ LU dan 125'39'15,87' BT; 03'30'39,84" LU dan $125^{\circ} 39^{\prime} 20,27^{\prime \prime} \quad$ BT; 033' $47,70^{\prime \prime}$ LU dan 125⒊'16,70"BT; 0330'47,00" LU dan $125^{\circ} 39^{\prime} 22,08^{\prime \prime}$ BT. Stasiun III di titik-titik koordinat $03^{\circ} 32^{\prime} 06,58^{\prime \prime}$ LU dan 125'39'34,26"BT; 03'32'07,85" LU dan 125 $39^{\circ} 35,07^{\prime \prime}$ BT; $03^{\circ} 32^{\prime} 05,74^{\prime \prime}$ LU dan 12539'35,39" BT; 03 $32^{\prime} 07,32$ " LU dan 12539'36,55" BT. Lokasi penelitian tampak pada Gambar 1.

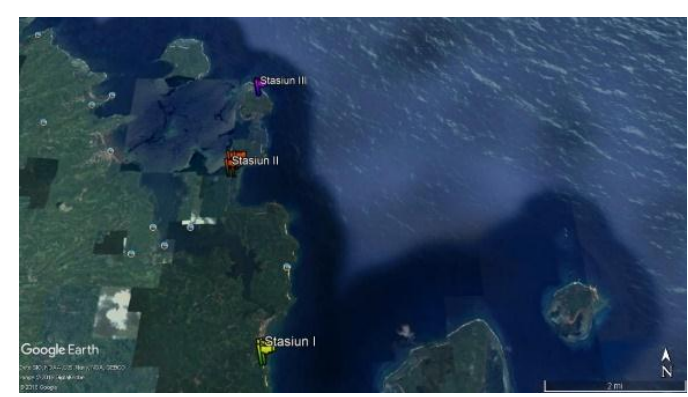

Gambar 1. Lokasi penelitian

Metode purposive sampling digunakan untuk penentuan lokasi penelitian. Pengambilan sampel di tempat yang telah ditentukan lokasinya dengan menggunakan metode transek jalur (line transect) (Fachrul 2007) dengan ukuran petak plot $1 \mathrm{~m} \times 1 \mathrm{~m}$.

Analisis struktur lamun yaitu Kepadatan Relatif, Frekuensi Relatif, Indeks Nilai Penting, dan Indeks Keanekaragaman Shannon-Wiener $\left(H^{\prime}\right)$. Indeks keanekaragaman Shannon-Wiener $\left(\mathrm{H}^{\prime}\right)$ dari Stilling (2012) yaitu:

$$
H^{\prime}=-\sum_{n=1}^{s} p i \ln p i
$$

dimana:

$\mathrm{H}^{\prime}=$ Indeks Keanekaragaman

$\mathrm{p}_{\mathrm{i}}=\mathrm{n}_{\mathrm{j}} / \mathrm{N}$

$n_{i}=$ Jumlah individu setiap jenis lamun

$\mathrm{N}=$ Jumlah individu seluruh jenis lamun

$S$ = banyaknya jenis lamun di lokasi penelitian

Nilai keanekaragaman akan dikelompokkan menjadi menjadi tiga (Fachrul 2007) yaitu: 
Jika $\mathrm{H}^{\prime} \leq 1$, keanekaragaman rendah, Jika $1<H^{\prime}<3$, keanekaragaman sedang

Jika H' > 3, keanekaragaman tinggi

\section{HASIL DAN PEMBAHASAN}

Jenis-jenis lamun yang ditemukan di ketiga stasiun sebanyak tujuh jenis yaitu Cymodocea rotundata, Cymodocea serrulata, Enhalus acoroides, Halodule uninervis, Halophila ovalis, Syringodium isoetifolium dan Thalassodendron ciliatum. Jumlah jenis lamun yang ditemukan tersebut berjumlah 7 dari 10 jenis lamun yang ditemukan di daerah pantai Sulawesi Utara.

Banyaknya jenis lamun dari ketiga stasiun secara berturut-turut sebanyak enam jenis di Stasiun I, tujuh jenis di Stasiun II, dan 4 jenis di Stasiun III. Jenis lamun di Stasiun II lebih banyak dibandingkan Stasiun I dan Stasiun III. Kehadiran jenis lamun E. acoroides yang hanya di Stasiun II menambah banyaknya jenis lamun di Stasiun II. Hal ini disebabkan Stasiun II memiliki substrat pasirlumpur yang sesuai bagi jenis lamun ini untuk tumbuh. Lamun $E$. acoroides umumnya tumbuh di teluk yang bersubstrat pasir-lumpur (Short dan Coles 2001). Stasiun I memiliki jumlah jenis lamun hampir sama dengan Stasiun II hanya dibedakan oleh $E$. acoroides yang tidak hadir di Stasiun I. Wagey (2013) menyebutkan lamun dapat tumbuh di semua jenis substrat tetapi umumnya lamun mendiami perairan yang bersubstrat lunak seperti pasir dan lumpur. Stasiun III memiliki substrat yang didominasi oleh bebatuan sehingga lamun yang tumbuh di stasiun ini terbatas jenisnya.

Nilai Kepadatan Relatif (KR) di Stasiun I yaitu $S$. isoetifolium $(48,60 \%)$, C. rotundata $(17,65 \%), C$. serrulata $(15,57 \%), \quad$ T. ciliatum $(13,54 \%), \quad H$. ovalis $(2,86 \%)$, dan $H$. uninervis $(1,78 \%)$. Nilai $\mathrm{KR}$ di Stasiun II, yaitu $S$. isoetifolium
$(43,31 \%), \quad$ C. serrulata $(24,36 \%)$, E. acoroides $(12,65 \%)$, C. rotundata $(12,47 \%), \quad$ T. ciliatum (4,72\%), $H$. ovalis $(2,27 \%), H$. uninervis $(0,23 \%)$. Nilai KR di Stasiun III, yaitu $S$. isoetifolium $(44,08 \%), C$. rotundata $(37,38 \%)$, C. serrulata $(15,01 \%)$, dan H. ovalis $(3,53 \%)$.

Lamun $S$. isoetifolium memiliki nilai kepadatan tertinggi di seluruh stasiun. Hal ini dikarenakan substrat yang ada di ketiga stasiun mendukung kehidupan lamun ini. Kepadatan jenis lamun dapat dipengaruhi oleh kondisi substrat dalam suatu wilayah (Short dan Coles 2001). Ketiga stasiun memiliki substrat yang dapat mendukung keberlangsungan hidup dari lamun $S$. isoetifolium. Lamun $S$. isoetifolim dapat ditemukan pada substrat yang berlumpur dan berpasir (den Hartog 1970; Kuo dan den Hartog 2006).

Lamun $S$. isoetifolium juga merupakan jenis lamun yang dominan dengan INP sebesar $70,15 \%$ yang diikuti oleh lamun $C$. rotundata sebagai lamun kodominan dengan INP sebesar 48,31\%. Pada Stasiun I, nilai INP tertinggi yaitu $S$. isoetifolium dengan jumlah $74,92 \%$ yang diikuti oleh $C$. rotundata dengan INP 49,23\%. Nilai INP tertinggi di Stasiun II juga dimiliki oleh $S$. isoetifolium, yaitu $65,31 \%$ dan $C$. serrulata, yaitu $48,36 \%$. Lamun

S. isoetifolium juga mempunyai nilai INP tertinggi di Stasiun III sebesar $70,75 \%$ dan C. rotundata sebesar $70,71 \%$ (Gambar 2).

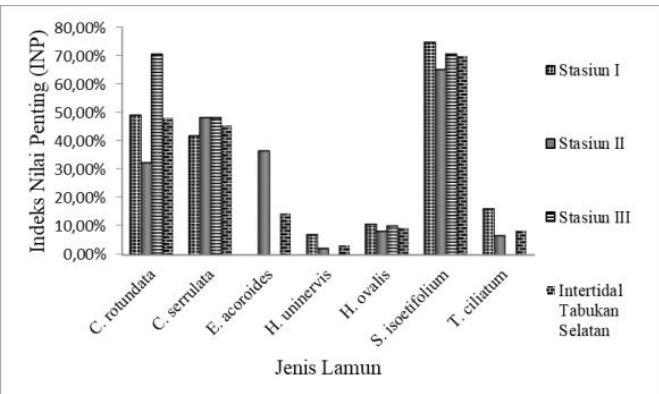

Gambar 2. Indeks nilai penting lamun 
Lamun $\quad S$. isoetifolium mendominasi ketiga stasiun. Hal ini menunjukkan bahwa lamun S. isoetifolium dapat beradaptasi dengan baik dibandingkan jenis lamun yang lain. Struktur morfologi yang kecil membuat lamun $S$. isoetifolium diuntungkan karena dapat dengan mudah tumbuh di antara lamun jenis lain sehingga hampir semua petak terdapat jenis lamun ini (Tolule 2015). Perbedaan substrat ketiga stasiun juga berpengaruh terhadap lamun jenis lainnya sehingga ada beberapa jenis lamun hanya dapat ditemukan di satu atau dua stasiun saja.

Nilai Indeks Keanekaragaman $\left(\mathrm{H}^{\prime}\right)$ lamun keseluruhan di lokasi penelitian sebesar 1,59 yang termasuk keanekaragaman tergolong sedang. Secara berturut-turut, nilai H' lamun di Stasiun I, Stasiun II, dan Stasiun III yaitu 1,52; 1,61; dan 1,23 (Gambar 3). Hal ini berarti nilai indeks keanekaragaman dari ketiga stasiun termasuk sedang.

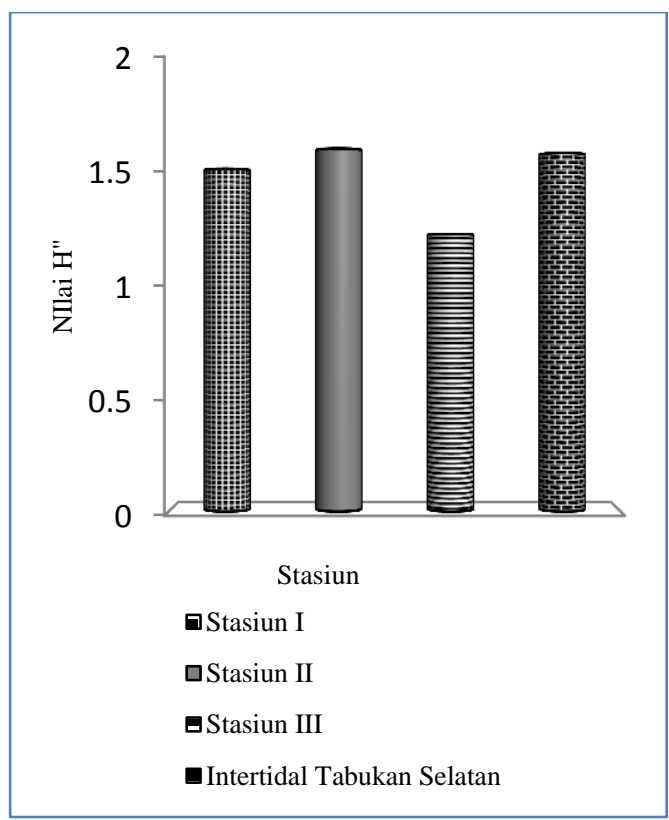

Gambar 3. Indeks keanekaragaman lamun

Keanekaragaman lamun di seluruh stasiun penelitian tergolong sedang. Keanekaragaman dipengaruhi oleh dua faktor yaitu kekayaan jenis dan kelimpahan individu tiap jenis. Kekayaan jenis berperan besar dalam mempengaruhi keanekaragaman jenis. Semakin tinggi jumlah jenis maka keanakeragaman jenis juga semakin meningkat.

Keanekaragaman lamun juga dipengaruhi oleh aktivitas manusia. Aktivitas antara lain mencari ikan, transportasi perahu bermotor dan pengambilan batuan. Aktivitas manusia tersebut dapat mempengaruhi keanekaragaman lamun yang ada di lokasi penelitian.

\section{KESIMPULAN}

Lamun yang ditemukan di Pantai Karurung, Palareng, dan Galoghong di Kecamatan Tabukan Selatan, Kabupaten Kepulauan Sangihe, Sulawesi Utara sebanyak tujuh jenis yaitu Cymodocea rotundata, Cymodocea serrulata, Enhalus acoroides, Halodule uninervis, Halophila ovalis, Syringodium isoetifolium, dan Thalassodendron ciliatum. Lamun S. isoetifolium memiliki nilai Kepadatan Relatif tertinggi di ketiga stasiun yang secara berturut, yaitu $48,60 \%, 43,31 \%$, dan $44,08 \%$. Secara berturut-turut, lamun $S$. isoetifolium juga memiliki Indeks Nilai Penting tertinggi di ketiga stasiun, yaitu $74,92 \%$, $65,31 \%$, dan $70,75 \%$. Keanekaragaman jenis lamun pada ketiga stasiun tergolong sedang dengan indeks $\mathrm{H}^{\prime}$ secara berturutturut, yaitu 1, 52; 1,61; dan 1,23. Secara menyeluruh keanekaragaman jenis lamun di Kecamatan Tabukan Selatan, Kabupaten Kepulauan Sangihe adalah 1,59.

\section{DAFTAR PUSTAKA}

Den Hartog C (1970) The Seagrasses of the world, North Holland Amsterdam.

Fachrul MF (2007) Metode sampling bioekologi, Bumi Aksara, Jakarta

Kuo J, den Hartog C (2006) Seagrass morphology, anatomy, and 
ultrastructure. Dalam: Larkum AWD, Orth RJ, Duarte CM (eds) Seagrasses: biology, ecology And conservation.

Netherlands, pp. 51-87.

Rahmawati S, Irawan A, Supriyadi IH, Azkab MH (2014). Panduan monitoring padang lamun, COREMAP CTI LIPI, Jakarta.

Short FT, Coles RG (2001) Global seagrass research methods.

Elsevier Science B.V,

Stilling P (2012) Ecology: global insights and investigations, McGraw-Hill, New York.

Tolule K (2015) Struktur komunitas lamun (seagrass) di Perairan Pantai Desa Bahoi Kecamatan Likupang Barat Kabupaten Minahasa Utara Sulawesi Utara. Skripsi. Universitas Sam Ratulangi Manado, Manado.

Wagey BT (2013) Hilamun (seagrass), Unsrat Press, Manado. 